\title{
A COMPARISON OF TURKEY-MALAYSIA LADM COUNTRY PROFILE FOR 3D CADASTRE PURPOSES
}

\author{
H.G. Sürmeneli a*, M. Alkanª , A. Abdul Rahman ${ }^{\mathrm{b}}$ \\ a YTU, Civil Engineering Faculty, Dept. of Geomatic Engineering, 34220 Esenler Istanbul, Turkey - (hsurmen, alkan)@ytu.edu.tr \\ ${ }^{\mathrm{b}}$ Department of Geoinformation, Faculty of Built Environment and Surveying, Universiti Teknologi Malaysia, UTM, Skudai 81310, \\ Johor, Malaysia-(alias)@utm.my
}

Commission 4, WG 7

KEY WORDS: LADM, 3D Cadastre, 3D Data Model, Land Administration

\begin{abstract}
This paper summarises the comparison of Turkish and Malaysian cadastral registration systems based on the Land Administration Domain Model (LADM, ISO 2012) associated with 2D and 3D cadastral situations. Literature review shows that many countries propose their profile based on the LADM, such as The Netherlands, Australia/ Queensland, China, Greece and others. Turkey and Malaysia are some of the potential candidates for the LADM based country profile, as described in this paper. The study presents a detailed overview of the Turkish and Malaysian cadastral system, and LADM-based country profiles developed by the two countries are compared thanks to the common ontology offered by LADM.
\end{abstract}

\section{INTRODUCTION}

Cadastral maps should provide complete information regarding record rights, restrictions and responsibilities (RRR) on the cadastral parcel (Kaufmann and Steudler, 1998; Stoter and Oosterom, 2007). However, although cadastral objects are three and four dimensions in most of the countries, they create cadastral maps that still mainly rely on 2D-based cadastral systems for current Land Administration Systems (LASs) (Ho et al., 2015; Atazadeh et al., 2016; Kalogianni et al., 2017; Rajabifard et al., 2018). Thus, RRR on the land cannot be adequately represented. The research and development in $3 \mathrm{D}$ cadastres hence have gained momentum over the last years. A very detailed and advanced analysis of studies in $3 \mathrm{D}$ cadastres in a wide range of countries worldwide can be found in the International Federation of Surveyors (FIG) 3D cadastres best practices book (Oosterom, 2018).

The most efficient standardised model in the land administration system (LAS) field is the Land Administration Domain Model (LADM). It was an ISO standard in 2012; ISO19152:2012 (ISO, 2012), which aims to establish a common ontology for RRR affecting land administration and its geometric components. Thus, it will enable communication between related parties within a country or between different countries (Atazadeh et al., 2017; Sürmeneli and Alkan, 2018; Sürmeneli and Alkan, 2020). Although LADMs current version provides an international framework for LAS, it is limited to support 3D cadastre lack of geometry or topology and time profiles (Kalogianni et al., 2020). Having a well created and maintained 3D cadastre will benefit many other applications such as urban planning and land and property management (Rajabifard et al., 2018). Legal and physical standards have been developed for these applications (LADM, CityGML, IFC/BIM, LandInfra etc.). While these standards can be used alone for each application, they can also be used to integrate each other (Sun et al., 2019).

Thanks to the advanced technology in geographic information science, 3D cadastral developments have matured with storage, analysis and visualisation of 3D objects (Kitsakis et al., 2016;
Dimopoulou et al., 2018; Su et al., 2019; Kalogianni et al., 2020). Within the scope of these developments, most countries have improved their cadastral systems according to the 2014 (Stuedler, 2014) and 2034 (ICSM, 2015) visions. While the first 3D cadastral registration has been made in the Netherlands (Stoter et al., 2017), a prototype for a 3D cadastre has been developed in Shenzhen, China, to support urban planning and management (Guo et al., 2013; Ying et al., 2015). Also, many academic studies have been carried out in Queensland and Victoria states of Australia, and physical models for 3D cadastre have been developed (Aien, 2013; Aien et al., 2015; Rajabifard et al., 2018), whereas research on the environmental impact of 3D public law restrictions in Greece is described (Kitsakis and Dimopoulou, 2020). The transformation of $2 \mathrm{D}$ analogue cadastral boundary plans into 3D digital information and visualisation in Stockholm, Sweden, is described in academic study (Larsson et al., 2020). The main motivation of the study is to show that the similar and different aspects of the cadastral systems of the countries are easily determined thanks to the LADM, which creates a common ontology. In the study, LADM-based cadastral models developed by Turkey and Malaysia were examined. Thus, it has become more understandable how the solutions developed for different registration systems are modelled.

The remainder of this paper describes the Turkish and Malaysia cadastral system and LADM in section 2. Section 3 discusses the comparisons, and finally the discussions and conclusion in section 4.

\section{THE TURKISH - MALAYSIA CADASTRAL SYSTEM AND LADM}

Turkish cadastre consists of two parts: land registry that represents the legal relationship between people and real properties, and the cadastral maps that, besides geometry data and annotations, contain the land-use. There is a title system, and it is under state guarantee in Turkey. The land registry records are officially formed by the title and the registry directorate and the maps by the cadastral branches. A 2D graphic representation of most rights, restrictions and responsibilities is possible. The 
rights, restrictions and responsibilities regarding the 3D are recorded as textual. Land registration and surveying are managed by the General Directorate of Land Registry and Cadastre (GDLRC). Also, the cadastral system and cadastral data have been improved and developed several projects due to digitisation. Such projects are called in Turkish TUCBS, Turkey National Spatial Data Infrastructure and TAKBIS, Land Registry and Cadastre Information System (Sürmeneli et al., 2020). TAKBIS project aims to create the Turkish Land Registry and Cadastre Information System across the whole country. TUCBS is an egovernment project aiming at establishing the infrastructure for Geographical Information System following the technological developments at the national level (Turkish National Geographic Information System-TUCBS) (Alkan et al., 2019).

Two different organisations manage the Malaysian cadastral system. The Department of Director General of Lands and Mines (DDGLM) and the Department of Survey and Mapping Malaysia (DSMM) are within the Ministry of Water, Land, and Natural Resources. One of the main aims of DSMM is serving cadastral survey information, which includes the dimension, size, and location of parcels. Thus, DSMM produces a Certified Plan (CP) within spatial components, including surveying and mapping cadastre parcels. On the other hand, the DDGLM, which deals with property ownership registration, is tasked with overseeing the legal aspects of land administration. The Land Registration System, which concerns the administrative (legal) data, is the responsibility of the Land Offices. The Land Office deals with ownership registration, namely, who owns the RRRs (Right, Responsible, Restriction). Each of these organisations has its different information management systems, namely the eTanah for the DDGLM and eKadaster in DSMM, which are two independent systems maintained in 2D. The Unique Parcel Identifier (UPI) was introduced to link the Land Office and DSMM, where every cadastral object has a unique identity number to differentiate from other cadastral objects. The Malaysian cadastral system deals with properties located on the surface level and above and below the surface level (Choon and Kam Seng, 2013; Zulkifli et al., 2015; WBG, 2017).

The land administration domain model is developed to contribute to Land Administration Systems (LAS). The land administration domain model has been established by ISO/TC211 with the aim of standardizing geographical information and geocharacteristics (Oosterom et al, 2006). The main objective of the LADM is to establish an ontology and facilitate the exchange of cadastral data with the shared land administration system (Oosterom et al, 2013). The main starting point of the LADM is to establish a common ontology for rights, restrictions and responsibilities affecting the land administration and its geometric components. Thus, it will enable communication between related parties within a country or between different countries (Oosterom et al., 2006; Lemmen et al., 2015). The LADM is developed in line with the Cadastre 2014 vision and complies with international ISO and OGC standards (Lemmen et al., 2009; Lemmen et al., 2011; Tjia and Coetzee, 2013). Besides, it has been conducted in the studies showing the compatibility of LADM with INSPIRE (Alkan and Polat, 2017). LADM has three main packages and one sub-package. These are LA_Party (Party package), LA_AdministrativePackage (Management package) and LA_SpatialUnitPackage (Spatial Unit package) and LA_SurveyingAndRepresentation (Figure 1).

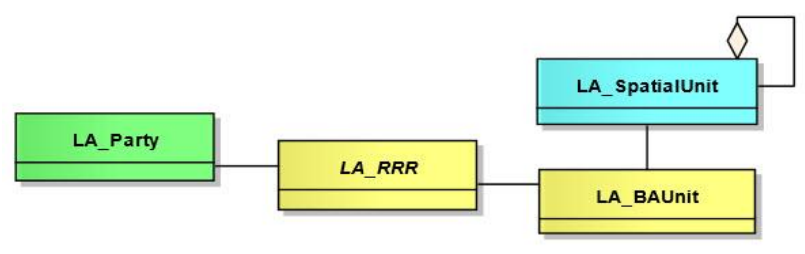

Figure 1. Basic packages of LADM (ISO19152).

\section{COMPARISON OF TURKISH AND MALAYSIA CADASTRAL MODEL BASED ON LADM}

\subsection{Turkish Cadastral Profile based on LADM}

The researchers developed the LADM-based 3D cadastral data model (Alkan and Polat, 2017; Sürmeneli and Alkan, 2018; Alkan et al., 2019; Alkan et al., 2020; Sürmeneli et al., 2020) was based on the analysis of the Turkish cadastral system. The model consists of 3 basic classes (TR_Party, TR_RRR and TR_RegistrationObject). The TR_Right class is divided into two sub-classes as property rights and limited rights. The property right is the right of the owner or legal persons to make all kinds of operations, such as the use of property, purchase, sale, rent, etc. The limited real rights class is divided into two sub-classes as mortgage and easement. The restriction class is the part of the information that restricts the use of limited real rights in the title registration, where the restriction information is registered, and the information is determined. These restrictions are subdivided into representations, rights and liability, annotations and mortgages in the land register. In this class person's obligations are represented. These obligations include pausing the tax on the real estate, maintenance, repair, easement according to the type of real estate. There may be one or more types of obligations. The SpatialUnit class is the parent class where all cadastral objects are represented and associated with the other classes. The SpatialUnit class comprises parcel sub-classes, buildings and independent sections. The parcel class is obligatory for the cadastral system. The building class has a composition relation type with the parcel class. So every building must be on a parcel. The condominium is considered a spatial unit. A building can have non or more independent parts. According to the Property Law, the Annex is outside of a condominium. Also, it is referred to directly as allocated to that section. The Annex cannot be registered alone in the land register. Therefore, the type of $0 .{ }^{*}$ (0-lots) relationship is selected between the condominium and Annex. Utility network, electricity, telephone, drinking water, sewerage, natural gas facilities are called technical infrastructure facilities. In the existing cadastral system in Turkey, utility networks are not registered to the land registry. The existence of a utility network is associated with the parcel or building. In addition, there may not be any utility network equipment under or above each parcel and building the existence facilities. The existing cadastral of a utility network is associated with the parcel or building. In addition, there may not be any utility network equipment under or above each parcel and building. Therefore, the UtilityNetwork class has a type of $0 . .^{*}$ ( 0 and many) relationships with structure and parcel class. Since the land registry is not registered, data related to the utility network facility cannot be kept directly in the system. Also, it can be provided with the external class TR_ExternalUtilityNetwork.Finally, the survey and representation sub-package is the package in which the spatial objects and the geometric status are represented together with the rights, restrictions and responsibility processes. The package 
represents geographic points, 2D and 3D borders, title and other resources. The attributes of the classes in the package have been created following the INSPIRE and LADM standards. Figure 2 shows the corresponding classes in Turkish conceptual model and the LADM data model.

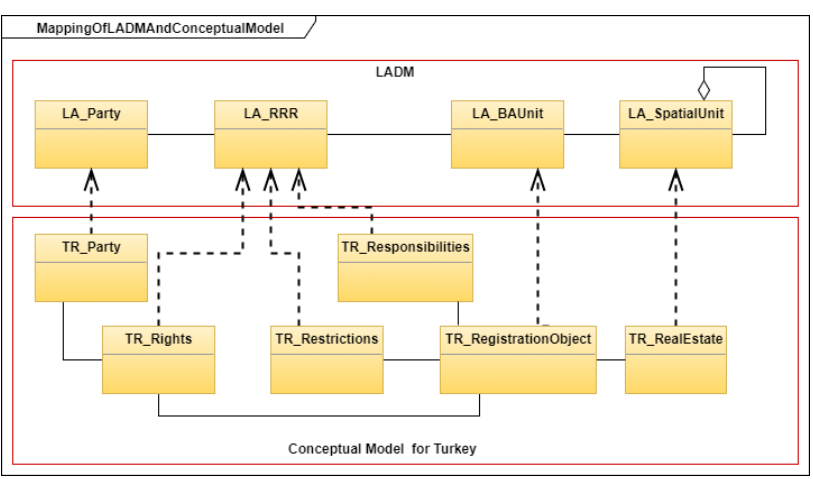

Figure 2. Turkish conceptual model based on the LADM schema (Alkan et al., 2020).

The LADM-based 3D cadastral data model developed by the researchers (Sürmeneli H.G. and Alkan M., 2020) was modeled in $4 \mathrm{D}$ by adding temporal attributes. The relationship of the developed model with international standards and LADM classes is shown in figure 3 .

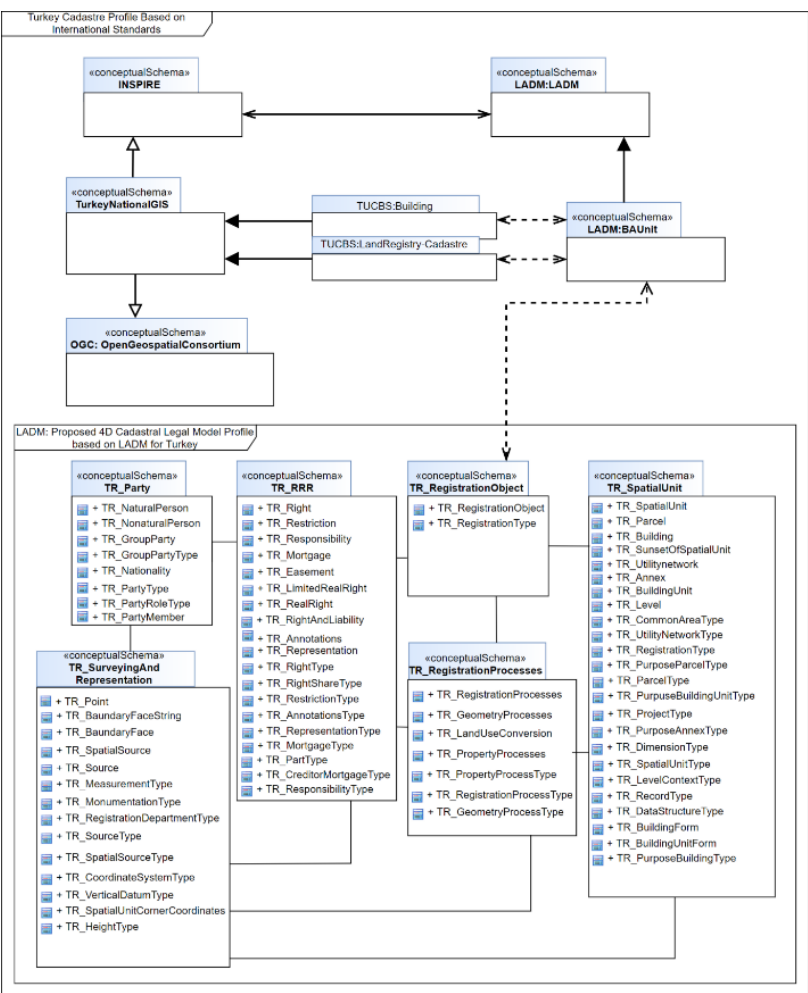

Figure 3. The proposed 4D cadastral legal model is associated with TUCBS sub-package themes based on international standards and LADM for Turkey (The hollow triangle arrow indicates the 'uses' status. A solid arrow indicates the 'dependent' status. The double arrow shows that they are in mutual relationship with each other. The dashed arrow relates the classes that correspond to each other)

\subsection{Malaysian Cadastral Profile based on LADM}

The development of the Malaysian LADM country profile is based on data sources from the District Land Offices and the Department Survey and Mapping Malaysia (DSMM). The Malaysian LADM country profile model was developed by Zulkifli et al., 2015 based on earlier studies (AbdulRahman et al. 2011; Tan and Looi, 2013; Zulkifli et al.,2013; Zulkifli et al., 2014). The Malaysian country profile is based on an inheritance from the LADM classes. the Malaysian LADM country profile contains the legal part and spatial part. The legal part has a party and administrative package (figure 4 ). The main class of the party package is MY_Party class with its specialization MY_GroupParty.There is an optional association class called MY_PartyMember. A party is a person or organization that plays a role in a rights transaction. The organization can be a company, a municipality or the state. A group party is any number of parties forming together a distinct entity. A party member is a party registered and identified as a constituent of a group party. The administrative package concerns the abstract class MY_RRR (MY_ Right, MY_Restriction and MY_Responsibility), MY_Mortgage, MY_BAUnit (Basic Administrative Unit) and MY_AdministrativeSource. A right is an action or activity that a system participant may perform or use an associated resource such as ownership, customary, easement and tenancy rights. A restriction is a formal or informal entitlement to refrain from doing something. Responsibility is a formal or informal obligation to do something such as maintaining a monument or a building. MY_Mortgage is a subclass of MY_Restriction. MY_Mortgage also is associated with the class MY_Right. A mortgage can be associated with $\left(0 . .^{*}\right)$ rights. A BAUnit is an administrative entity consisting of zero or more (parcels) against which one or more unique and homogeneous rights, responsibilities or restrictions are associated with the whole entity as included in the Land Administration System (Zulkifli et al., 2015).

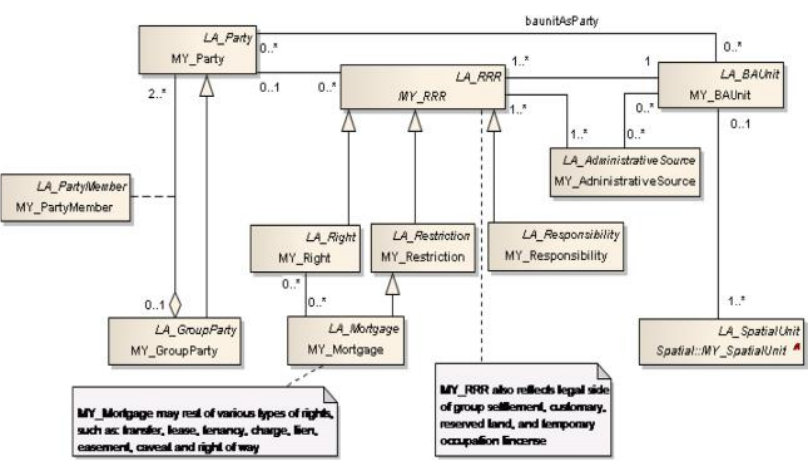

Figure 4. Overview of administrative (legal) part of the Malaysian LADM country profile (Zulkifli et al., 2015).

The spatial unit can be $2 \mathrm{D}$ or $3 \mathrm{D}$. The lots are $2 \mathrm{D}$, but subsurface lots exist with 3D volumetric descriptions without 3D topology. MY_GenericLot holds the attributes of a lot, and it has two specialisations, MY_Lot2D and MY_Lot3D, with their attributes and structure. MY_Lot2D is based on 2D topology concerning shared boundaries (MY_ BoundaryFaceString). In 3D, topology is not available for lots (MY_ Lot3D) and strata objects. In the model, one strata object type remains represented in 2D, that is MY_LandParcel (with buildings no more than four storeys). The other strata objects are proposed to be $3 \mathrm{D}$ and inherit from an abstract class MY_Shared3DInfo, with strata specialisations (and mutual aggregation relationships): MY_BuildingUnit, MY_ParcelUnit, 
MY_CommonPropertyUnit MY_LimitedCommonPropertyUnit.

and

LimitedCommonPropertys modelled as a part-of relationship to MY_CommonProperty(the aggregation class). MY_Level class is used to organise the various types of spatial units. There is a type attribute in the MY_Level class that describes the level type of the spatial unit, and such MY_Level is a collection of spatial units with a geometric or thematic coherence. MY_SpatialSource has an association with MY_SpatialUnit and MY_Point (figure $5)$.

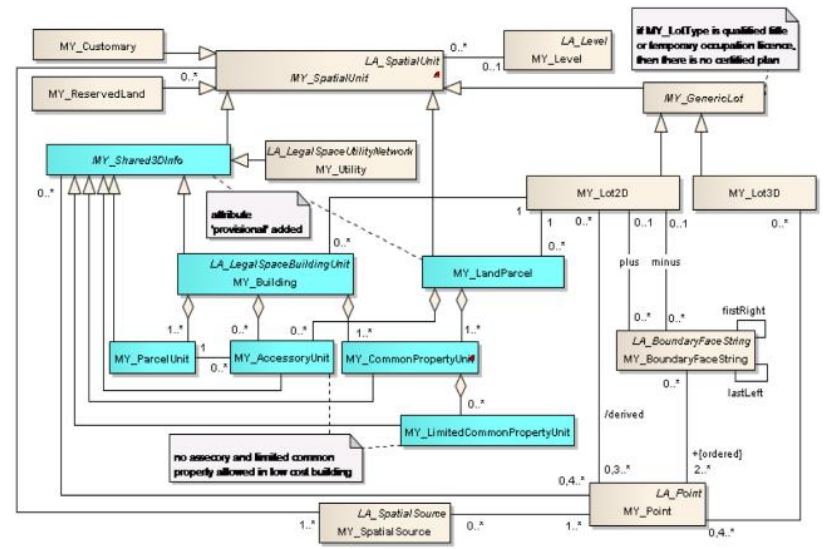

Figure 5. Overview of the spatial part of the Malaysian LADM country profile (Zulkifli et al., 2015).

3.3 Comparison of LADM Countries Model Between Turkey and Malaysia
Although there are differences in the cadastral systems of the two countries, they have many similarities in general. They carry out projects for the improvement of cadastral systems in both countries. In addition, academic and institutional studies are carried out for the transition to $3 \mathrm{D}$ cadastre. There are two essential differences in the cadastral system between the two countries. First, while it is possible to register the temporal information about real estate in the Turkish cadastral system, there is no temporal registration in Malaysia. However, the developed LADM model provides innovation for the Malaysian cadastral system. Secondly, it allows the registration of 3D real estate in Malaysia underground and above ground. However, the Turkish cadastral system gives this information in textual (mainly underground structures). Thanks to the common ontology provided by LADM, the differences and similarities in the cadastral systems between the two countries can be compared and understood more clearly. Table 1 shows the comparison of LADM classes and the country profiles based on LADM developed by the two countries. Generally developed packages are the same. Only some classes in the packages show differences. In particular, the classes defined as spatial units are different. Each class is explained in detail in section 3.1 and 3.2. These are: Party, Administrative, Spatial Unit and Surveying and Representations Packages respectively. The LA_Party Package describes the owners, right holders. LA_SpatialUnit Package described spatial units (e.g. parcel, building, apartment) and was mapped to the abstract class RealEstate. LA_RRR describes the rights, restrictions, and responsibilities over the property. The LA_BAUnit class represents a basic administrative unit, a set of rights, restrictions, and responsibilities of one or more real properties. Surveying and Representation classes are TR_Point, TR_SpatialSource, and TR_BoundaryFaceString.

\begin{tabular}{|c|c|c|}
\hline LADM Classes & Turkey 3D Conceptual Model Classes & Malaysian 3D Conceptual Model Classes \\
\hline \multicolumn{3}{|c|}{$\begin{array}{l}\text { Package Party } \\
\end{array}$} \\
\hline LA_Party & TR_Party & MY_Party \\
\hline LA_GroupParty & TR_GroupParty & MY_GroupParty \\
\hline LA_PartyMember & TR_PartyMember & MY_PartyMember \\
\hline \multicolumn{3}{|c|}{ Administrative Package } \\
\hline LA_RRR & TR_RRR & MY_RRR \\
\hline LA_Right & TR_Right & MY_Right \\
\hline LA_Restriction & TR_Restriction & MY_Restriction \\
\hline LA_Responsibility & TR_Responsibility & MY_Responsibility \\
\hline LA_Right & TR_Easement & $-1-$ \\
\hline LA_BAUnit & TR_RegistrationObject & - \\
\hline LA_Mortgage & TR_Mortgage & MY_Mortgage \\
\hline LA_RRR & TR_Annotations & - \\
\hline LA_RRR & TR_Representation & - \\
\hline LA_RRR & TR_RightAndLiability & - \\
\hline LA_AdministrativeSource & TR_AdministrativeSource & MY_AdministrativeSource \\
\hline LA_RRR & TR_RegistrationProcesses & - \\
\hline LA_RRR & TR_GeometryProcesses & - \\
\hline LA_RRR & TR_LandUseConversion & - \\
\hline LA_RRR & TR_PropertyProcesses & - \\
\hline \multicolumn{3}{|c|}{ SpatialUnit Package } \\
\hline LA_SpatialUnit & TR_SpatialUnit & MY_SpatialUnit \\
\hline LA_SpatialUnit & TR_Parcel & MY_LandParcel \\
\hline LA_Level & TR_Level & MY_Level \\
\hline LA_SpatialUnit & TR_Building & - \\
\hline LA_SpatialUnit & - & MY_Customary \\
\hline LA_SpatialUnit & - & MY_ReservedLand \\
\hline LA_SpatialUnitGroup & TR_SpatialUnitGroup & - \\
\hline
\end{tabular}




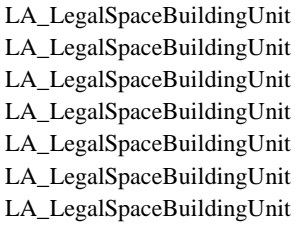

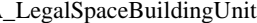
LA LegalSpaceBuildingUnit LA_LegalSpaceBuildingUnit LA_LegalSpaceBuildingUnit

\author{
TR_BuildingUnit \\ TR_Annex \\ TR_CommonArea
}

\author{
MY_Building \\ MY_ParcelUnit \\ MY_AccessoryUnit \\ MY_CommonPropertyUnit \\ MY_LimitedCommonPropertyUnit \\ MY_Shared3DInfo
}

\begin{tabular}{ccc} 
LA_LegalSpaceUtilityNetwork & TR_UtilityNetwork \\
LA_BAUnit & TR_RegistrationObject & MY_Utility \\
LA_RequiredRelationshipSpatialUnit & TR_RequiredRelationshipSpatialUnit & - \\
\hline & Surveying and Representation Sub_Package & MY_Point \\
LA_Point & TR_Point & MY_SpatialSource \\
LA_SpatialSource & TR_SpatialSource & MY_BoundaryFaceString \\
LA_BoundaryFaceString & TR_BoundaryFaceString & - \\
LA_BoundaryFace & TR_BoundaryFace & MY_Lot2D \\
LA_BoundaryFaceString & - & MY_Lot3D \\
LA_BoundaryFaceString & - & MY_GenericLot \\
LA_BoundaryFaceString & & \\
\hline
\end{tabular}

Table 1. Comparison of LADM classes with the proposed 3D conceptual data model classes developed by Turkey and Malaysia

\section{DISCUSSIONS AND CONCLUSION}

In this study, the cadastral systems of Turkey and Malaysia were evaluated, and LADM-based cadastral data models were examined for the transition to 3D cadastre. Thanks to the LADMbased cadastral data models developed by Turkey and Malaysia, country profiles can be explained more clearly. As an international standard, LADM provides an opportunity to improve Malaysia's and Turkey's land management systems. There are many improvements and benefits that LADM can bring to both countries. Significantly, internal operations of land offices in Malaysia vary; as such, the way land administration data is recorded and used are different. It has resulted in database systems that are different in structure and schema. While it may not be practical or viable to make the databases consistent at the national level, LADM provides an opportunity for harmonising the data when there is a need to integrate the databases for national interests. Database systems of the land office can be mapped to LADM to provide a common ground for understanding how different data elements are described and

\section{REFERENCES}

Abdul Rahman, A., Teng, C.H., Van Oosterom, P.J.M., 2011. Embedding 3D into multipurpose cadastre. In: FIG Working Week 2011 - Bridging the Gap between cultures, 18-22 May 2011, Marrakech, Morocco. Bydlosz, J., 2013.

Aien, A., 2013. 3D Cadastral data modelling. PhD Thesis, Melbourne University, Victoria, Australia.

Aien, A., Rajabifard, A., Kalantari, M.; Shojaei, D., 2015. Integrating Legal and Physical Dimensions of Urban Environments. ISPRS Int. J. Geo-Inf. 4(3): p. 1442-1479.

Alkan, M. and Polat, Z.A., 2017. Design and development of LADM-based infrastructure for Turkey. Survey Review, 49:356, 370-385.

Alkan M., Gürsoy Sürmeneli H., Polat Z.A., 2019. Design and determine cadastral and land management performance of Turkey with Cadastre 2034 Vision. XXVI FIG Congress, Istanbul, Türkiye, 6-11 May. used. For Turkey, the LADM is used to create 3D terminology and establish a common ontology. The objects registered in the cadastral system are defined, and the relations between the owners are represented. LADM standard facilitates the sharing of 3D digital land administration data with other jurisdictions since LADM provides a standardised approach for exchanging land administration data among all jurisdictions. Thus, it enabled the introduction of the Turkish cadastral system in national and international platforms during the transition to 3D cadastre with its legal aspects. One of the development purposes of LADM is to create a common ontology for different countries and cadastral systems. In this study, thanks to the common ontology presented by LADM, the cadastral systems of the two countries could be easily compared. Thus, the differences and similarities between the systems could be examined. Both countries improve their cadastral systems and develop models based on LADM for 3D cadastral studies, promoting their countries on international platforms. In addition, they will be able to set an example for other countries that plan to develop a cadastral model using LADM.

Alkan M., Sürmeneli H.G. and Polat Z. A., 2020. Design and development 3D RRR model for Turkish cadastral system using international standards. Survey Review, cilt.1, ss.1-14.

Atazadeh, B., Kalantari, M., Rajabifard, A., Champion, T. and Ho, S., 2016. Harnessing BIM for 3D Digital Management of Stratified Ownership Rights in Buildings. FIG Working Week 2016: Recovery from Disaster, Christchurch, New Zealand 2-6 May.

Atazadeh, B., Rajabifard, A. and Kalantari, M., 2017. Assessing performance of three BIM Based views of buildings for communication and management of vertically stratified legal interests. ISPRS Int. J. Geoinf. (6), 198.

Choon, T.L. and Kam Seng, L., 2013. Towards Malaysian Multipurpose 3D Cadastre base on Land Administration Domain Model (LADM)-An Empirical Study. International FIG workshop on the Land Administration Domain Model 24-25 September 2013, Kuala Lumpur, Malaysia. 
Dimopoulou, E., Karki, S., Roić, M., de Almeida, J.P.D., Griffith-Charles, C., Thompson, R., Ying, S., Paasch, J. and Van Oosterom, P.J.M., 2018. Initial Registration of 3D Parcels. (Chapter 2 - FIG Publication (2018) 3D Cadastres Best Practices - Extended Version, Editor: Van Oosterom, P.J.M.).

Guo, R., Li, L., He, B., Luo, P. Ying, S., Ziang, R., 2013. Developing a $3 \mathrm{D}$ cadastre for the administration of urban land use: A case study of Shenzhen, China. Computers, Environment and Urban Systems, 40, 46-55.

Ho, S., Rajabifard, A. and Kalantari, M., 2015. Invisible constraints on 3D innovation in land administration: A case study on city of Melbourne. Land Use Policiy, 42, 412-425.

ICSM. , 2015. A Vision for Cadastre 2034.

ISO19152,2012. ISO 19152. International Standard, Geographic Information- Land administration domain model (LADM).

Kalogianni, E., Dimopoulou, E., Quak, W., Germann, M., Jenni, L., van Oosterom, P.J.M., 2017. "INTERLIS language for modelling legal 3D spaces and physical 3D objects by including formalized implementable constraints and meaningful code lists" ISPRS Int. J. Geoinf. 6 (10), 319 Special Issue: Research and Development Progress in 3D Cadastral Systems.

Kalogiannia. E, Dimopouloub, E., Thompsona, R.J., Lemmen, C., Ying, S., Van Oosterome, P., 2020. Development of 3D spatial profiles to support the full lifecycle of 3D objects. Land Use Policy, 98, 10417.

Kaufmann, J. and Steudler, D., 1998. FIG. Cadastre 2014, a vision for a future cadastral system. Technical report, Federation International des Geometers, Commission 7.

Kitsakis, D., Apostolou, C. and Dimopoulou, E., 2016. Three dimensional cadastre modelling of customary real estate rights. Survey Review, DOI: 10.1080/00396265.2016.1252518

Larsson, K., Paasch J.M. and Paulsson, J., 2020. Representation of 3D cadastral boundaries - From analogue to digital. Land Use Policy, 98, 104178.

Lemmen, C., Van Oosterom, P., Uitermark, H., Thompson, R., and Hespanha, J.P. 2009. Transforming the land administration domain model (LADM) into an ISO standard (ISO19152). FIG working week, Eilat, Israel. <http://www.gdmc.nl/publications/2009/LADM_to_ISO_Stand ard.pdf $>$.

Lemmen, C. H. J., Van Oosterom, P. J. M., Uitermark, H. T., Zevenbergen, J. A. and Cooper, A. K., 2011. Interoperable domain models: the ISO land administration domain model LADM and its external classes. UDMS 2011, Delft, The Netherlands, 28-30 September.

Lemmen, C., Van Oosterom, P. and Bennett, R., 2015. The land administration domain model. Land Use Policy, 49, 535-545.

Oosterom, P.J.M., 2018. Best Practices 3D Cadastres - Extended version International Federation of Surveyors, Copenhagen, Denmark, March 2018 (ISBN 978-87-92853-64-6, ISSN: 23118423).

Oosterom, P. J. M., Lemmen, C., Ingvarsson, T., van der Molen, P., Ploeger, H., Quak,W., Stoter, J. and Zevenbergen, J., 2006.
The core cadastral domain model. Computers, Environment and Urban Systems, 30, pp.627-60.

Oosterom, P., Lemmen, C. and Uitermark, H., 2013. ISO 19152:2012, land administration domain model published by ISO. FIG Working Week 2013. Environment for Sustainability. Abuja, Nigeria, 6-10 May.

Rajabifard A., Atazadeh B. and Kalantari M., 2018. A critical evaluation of 3D spatial information models for managing legal arrangements of multiowned developments in Victoria, Australia. International Journal of Geographical Information Science, 32:10, 2098-2122.

Sun J., Mi S., Olsson P., Paulsson J. and Harrie L., 2019. Utilizing BIM and GIS for Representation and Visualization of 3D Cadastre. ISPRS Int. J. Geo-Inf., 8, 503; doi:10.3390/ijgi8110503.

Sürmeneli, H. G., Koeva, M. N., Zevenbergen, J. A., and Alkan, M., 2020. Towards integration of LADM and CityGML for the cadastral system of turkey, Int. Arch. Photogramm. Remote Sens. Spatial Inf. Sci., XLIII-B4-2020, 691-698, https://doi.org/10.5194/isprs-archives-XLIII-B4-2020-691-2020

Sürmeneli H.G. and Alkan M., 2018. Design and determine 3D cadastral systems: a case study of Turkey. 6th International FIG 3D Cadastre Workshop, Delth, Netherlands, 447-464, 2-4 October.

Sürmeneli H.G. and Alkan M., 2020. Towards standardisation of Turkish cadastral system using LADM with 3D cadastre. Survey Review. Doi: 10.1080/00396265.2020.1855700.

Stuedler, D., 2014. CADASTRE 2014 and Beyond.

Stoter, J. E. and Van Oosterom, P.J.M., 2007. Technological aspects of a full 3D cadastral registration. International Journal of Geographical Information Science, 19:6, 669-696.

Stoter, J.E., Ploeger, J., Roes, R., van der Riet, E., Biljecki, F., Ledoux, H., Kok, D., Kim, S., 2017. Registration of multi-level property rights in $3 \mathrm{D}$ in the Netherlands: two cases and next steps in further implementation. ISPRS Int. J. Geoinf. 6 (6), 158.

Tan, L.C., Looi, K.S., 2013. Towards a Malaysian multipurpose 3D cadastre basedon the Land Administration Domain Model (LADM) - an empirical study. In:Proceedings of the 5th FIG Land Administration Domain Model Workshop,24-25 September 2013, Kuala Lumpur, Malaysia, pp. 109-132.

Tjia, D. and Coetzee, S. , 2013. Application of the land administration domain model to the city of johannesburg land information system. South African Journal of Geomatics, 2(3), pp.260-79.

Ying, S., Guo, R., Li, L., Van Oosterom, P.J.M. and Stoter, J., 2015. Construction of 3D volumetric objects for a 3D cadastral $\begin{array}{llllll}\text { system. } & \text { Trans. } & \text { Gis } & 19 & \text { (5), } & \text { 758-779. }\end{array}$ https://doi.org/10.1111/tgis.12129.

Zulkifli, N. A., Abdul Rahmana, A., van Oosterom, P., Choona, T., Jamil, H., Hua, T., Seng, L., Lim, C., 2015. The importance of Malaysian Land Administration Domain Modelcountry profile in land policy. Land Use Policy 49, 649-659.

Zulkifli, N.A., Abdul Rahman, A., van Oosterom, P., 2013. Developing 2D and 3Dcadastral registration system based on 
LADM: illustrated with Malaysian cases.In: Proceedings of the 5th FIG Land Administration Domain Model Workshop,24-25 September 2013, Kuala Lumpur, Malaysia, pp. 447-464.

Zulkifli, N.A., Abdul Rahman, A., Jamil, H., Teng, C.H., Tan, L.C., Looi, K.S., Chan, K.L.,van Oosterom, P., 2014. Towards Malaysian LADM country profile for 2D and3D cadastral registration system. In: Proceedings of FIG Congress 2014, 1621June 2014, Kuala Lumpur, Malaysia.

WBG, 2017. Malaysia's Experience with Transforming Land Administration, Word Bank Group. 